CLAWAR 2019: 22nd International Conference on

Climbing and Walking Robots and the Support

Technologies for Mobile Machines,

Kuala Lumpur, Malaysia, 26-28 August 2019.

https://doi.org/10.13180/clawar.2019.26-28.08.31

\title{
FUZZY-PID BASED CONTROLER FOR ACTIVE VIBRATION CONTROL OF NONLINEAR DYNAMIC SYSTEMS
}

\author{
MUHAMAD SUKRI HADI \\ Faculty of Mechanical Engineering, Universiti Teknologi MARA, 40450, Shah Alam, Selangor, Malaysia \\ E-mail: msukrihadi@uitm.edu.my
}

HANIM MOHD YATIM, MAT HUSSIN AB TALIB, INTAN ZAURAH MAT DARUS

School of Mechanical Engineering, Universiti Teknologi Malaysia, 81300, Skudai, Johor, Malaysia

E-mail: hanim.my@utm.my,mathussin@utm.my,intan@utm.my

ANNISA JAMALI

Faculty of Engineering, Universiti Malaysia Sarawak, 94300, Kota Samarahan, Sarawak, Malaysia

E-mail: jannisa@unimas.my

\begin{abstract}
The light weight characteristic offered by flexible structures can be easily influenced to the excessive vibration and it also brings several problems including instability, fatigue, bending and low performance. Therefore, it is compulsory to suppress the undesired vibration of flexible structures due to sustain its performance. This paper presents the development of hybrid controller known as fuzzy-PID based controller for vibration suppression of the horizontal flexible plate structure. Initially, the experimental rig was designed and integrated with the instrumentation system for vibration data collection purpose. The vibration data obtained experimentally was used to model the dynamic system based on auto-regressive with exogenous input structure using evolutionary swarm algorithm. The model obtained in simulation environment was then used for the development of PID-Fuzzy based controller. The performance of proposed controller was validated by exerting two types of disturbances to the system for robustness verification. It was indicated that PID-fuzzy controller was achieved higher attenuation value at the first mode of vibration by achieving $32.14 \mathrm{~dB}$ attenuation in the system. The attenuation value has been reduced from $103.5 \mathrm{~dB}$ to $71.36 \mathrm{~dB}$, equivalent to $31.05 \%$ attenuation, after the introduction of vibration control. The mean squared error achieved by the controller is 0.0237 , compared with 0.6655 before the activation of controller.
\end{abstract}

\section{Introduction}

Recently, it becomes a growing trend among the industries to reduce the weight of mechanical structures for minimizing the production cost and increasing the system effectiveness. Meanwhile, the characteristics offered by the flexible plate structure such as lightweight, faster response, less power consumption and less bulky design have received significant considerations by the industries to apply its advantages into their engineering applications. The flexible plate has been used in numerous industry applications such as aircraft body, automotive structure, robotic arm, electronic board design, bridge decks, and conveyor system [1].

Nevertheless, the vibration of the flexible plate structure is a critical problem faced by the industries, particularly in the airport baggage transport conveyor, micro hand surgery system and semiconductor manufacturing industry which have a light weight characteristic and relatively low damping for the fundamental and initial models. This drawback is often a limiting factor in the structure performance that can lead to the instability, fatigue and structural damages. Moreover, the frequency associated with this structure is commonly low which makes the nodes vibration control become an important issue for the light flexible structures [2,3]. 
Due to this problem, it brings the idea to control the unwanted vibration using passive and active control methods. Nevertheless, the passive control method has two major obstacles which are ineffective at low frequency range and only efficient for a narrow band of frequency. In fact, an active vibration control (AVC) method is more efficient, reliable and flexible in controlling the unwanted vibration of flexible structure. The potential of active vibration has been received remarkable attention from the researchers for effective vibration suppression in many engineering applications $[4,5]$.

This paper presents the development of Fuzzy-PID based controller for vibration suppression of horizontal flexible plate system. The model of the system will be developed using system identification via evolutionary warm algorithm based on input-output vibration data collected experimentally. An approximate model achieved in this study will be used as a platform of Fuzzy-PID based controller development.

\section{Active Vibration Control}

Recently, it becomes a growing trend among the industries to implement lightweight of mechanical structures to their applications. However, a major consideration that needs to be taken into account is the system vibration arising from the structural flexibility. The flexible plate is easily affected by external force which will lead to vibration on the system. A large number of discrete frequencies in the system will generate high amplitude of vibrations, which will lead to some issues such as noise, fatigue, wear, failure, and may decrease the performance of the flexible plate system. Thus, active vibration control (AVC) is proposed to overcome the problems related to low frequency system. The concept of AVC technique is to cancel the vibration at a desired location using the superposition of waves by generating secondary vibration of destructive interferes with unwanted vibration source $[6,7]$.

In order to achieve a satisfactory result in suppressing the unwanted vibration of the system, hence, the horizontal flexible plate system need to be modelled properly. Finite difference method (FDM) and finite element method (FEM) are popular approaches which has been applied by many researchers on the dynamic behaviour development of flexible plate systems previously. However, the disadvantages of this methods are computational complexity and consequent software involved in its formulations. To date, system identification technique is one of the potential candidates in obtaining the accurate model of dynamic systems based on input and output data. Many researchers have used system identification approach in modelling the flexible structure system [8].

In this research, the dynamic model system has been developed using evolutionary swarm algorithm via particle swarm optimization based on input-output vibration data obtained experimentally and the transfer function obtained will be used in the development of controller for vibration suppression of horizontal flexible plate. Details regarding PSO algorithm and modeling results can be found in [9]. The transfer function obtained using PSO modeling is described as in the Equation (1).

$$
\frac{0.3483 z^{-1}-0.002182 z^{-2}}{1-1.414 z^{-1}+0.9931 z^{-2}}
$$

\section{Fuzzy-PID based Controller}

Many strategies have been proposed by researchers to obtain the best tuning method where improper tuning method may lead to poor robustness, cyclic and slow recovery of the system. Therefore, this research presents the development of hybrid controller known as Fuzzy-PID 
based controller (F-PID) for vibration cancellation of the horizontal flexible plate system. The main aims is to achieve the best tuning methods and better control strategy for further improvement of the control performance. The developed hybrid controller will be developed in a MATLAB/Simulink environment and validated by exerting different types of disturbances into the system.

The F-PID based controller is proposed due to its advantages in providing an effective methodology to develop the controller without using advanced mathematics. The details regarding the fuzzy controller can be described as follows:

i. Fuzzification

Fuzzification is a process of transforming crisp values into grades of membership for linguistic terms of fuzzy sets. The fuzzification process generates and extracts the membership functions (MFs) of input and output variables, then converting those into the linguistic variables [10].

ii. $\quad$ Fuzzy Rule Base

The fuzzy rule base is the set of condition which needs to be followed by the fuzzy system in order to achieve the system output based on the given input. The dynamic behaviour of fuzzy system can be described in the linguistic rules of the fuzzy set and correlated in IF-THEN form [11].

iii. $\quad$ Fuzzy Inference System

Fuzzy inference system (FIS) is defined as a system that uses fuzzy set theory in mapping input to the outputs. The mapping provides a basic from which decisions can be made or patterns discerned. The purpose of inference is to justify the fuzzy input to the rule base on one hand and generate the fuzzy output for every rule by identifying the rule output in the space on the other [12].

Figure 1 shows the block diagram of F-PID based controller used in this study. Based on the PID parameters tuned by Ziegler-Nichols tuning rules, the fuzzy system will select the best values of $K_{P}, K_{I}$ and $K_{D}$ with the chosen disturbance applied on the system before feeding the signal into the PID controller. Usually, the fuzzy structure is developed based on error, $e$ and change of error $d e / d t$ which applied as input in the fuzzy system. All of the fuzzy operations will be simulated using MATLAB/Simulink and the operation is used to determine the best parameters due to achieve the higher attenuation at the first mode of vibration for vibration suppression of horizontal flexible plate system. Figure 2 presents the F-PID based controller scheme in MATLAB/Simulink.

\section{Results and Discussions}

In this study, the trapezoidal shapes membership function is used for both input variables (error (e) and derivative error (de/dt)) while Gaussian curve membership function is used for the whole output variables. The MFs is selected in this study and frequently chosen by many researchers because of its simplicity and convenience. The input interval for error is [-2 2] and the input interval for derivative error is [-1 1$]$. For the output interval, the value is determined based on 
Ziegler-Nichols value. Thus, the outputs interval used in this study are [3.5 4], [0.01 0.03] and [3.5 4] for KP, KI and KD, respectively.

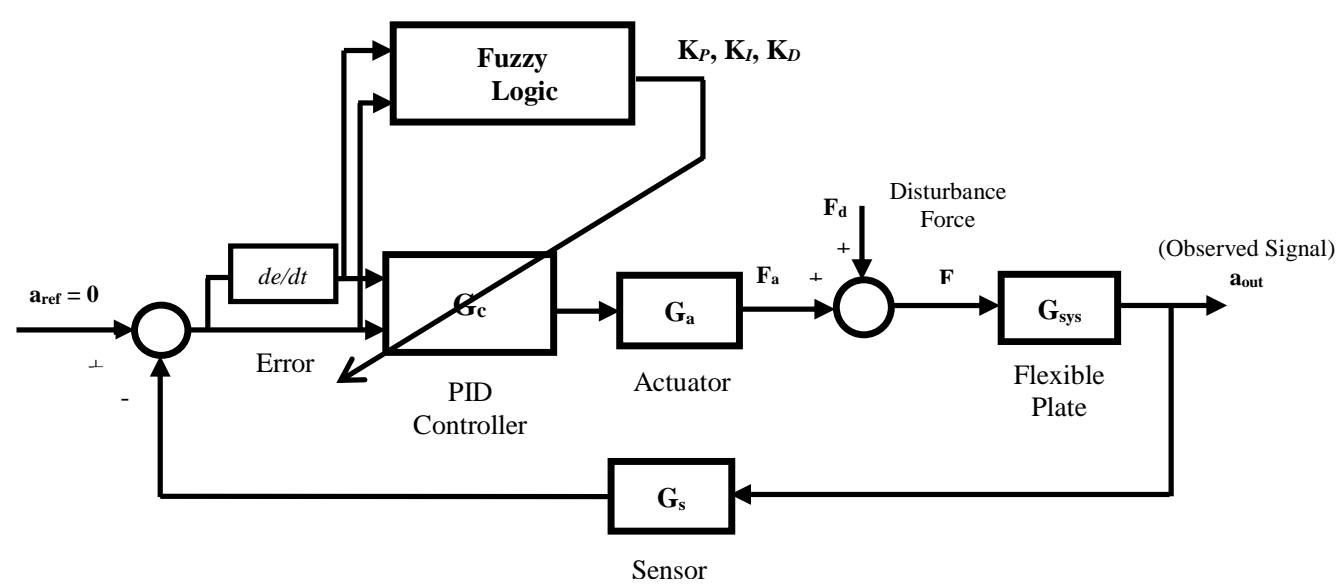

Figure 1. The block diagram of F-PID based controller.

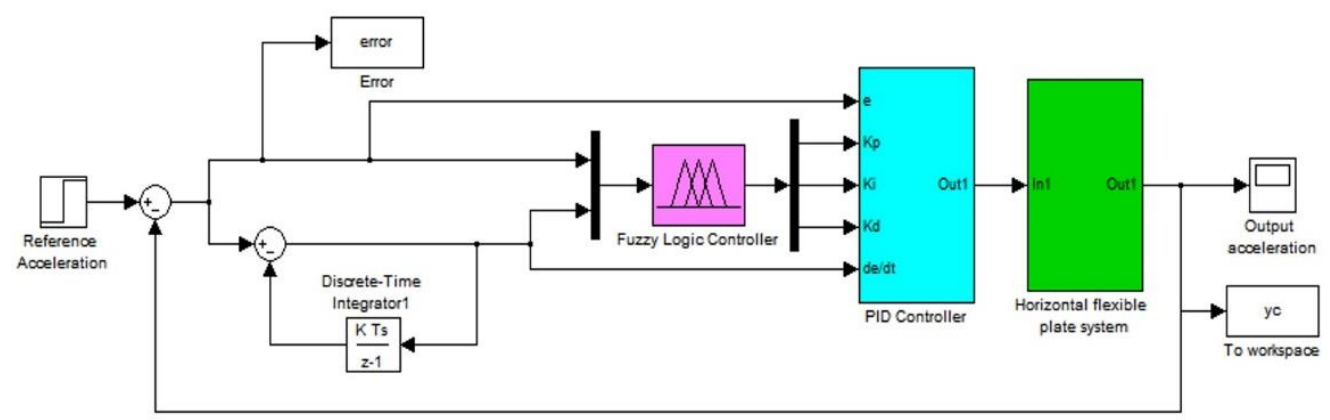

Figure 2. The block diagram of F-PID based controller in MATLAB/Simulink environment.

There are five linguistic descriptions used in the F-PID based controller known as negative large (LN), negative small (SN), zero (ZE), positive small (SP) and positive large (LP). The input and output membership functions used in the F-PID based controller are displayed in Figures 3 and 4, respectively. Table 1 describes the 25 rules based for F-PID based controller used in this study.
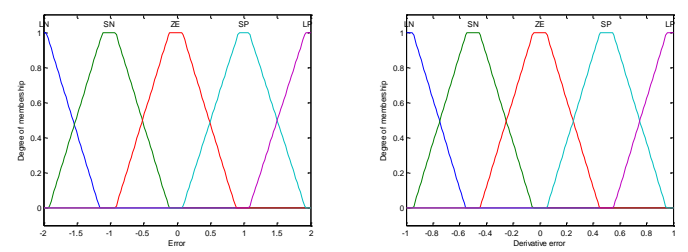

Figure 3. Input membership function used in the F-PID based controller 

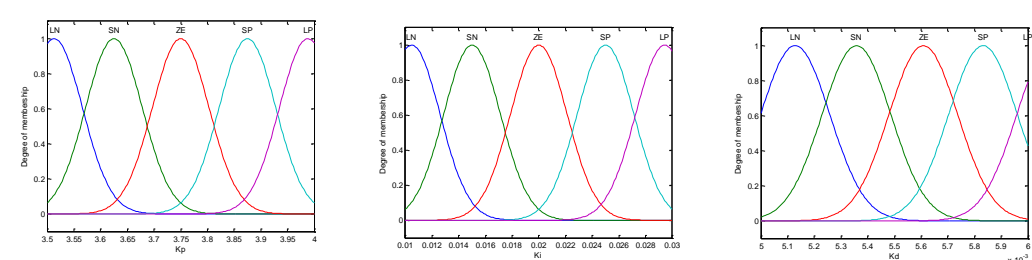

Figure 4. Output membership function used in the F-PID based controller

Table 1. Rule based used in the control scheme

\begin{tabular}{|c|c|c|c|c|c|c|}
\hline \multirow{2}{*}{\multicolumn{2}{|c|}{ Fuzzy Rules }} & \multicolumn{5}{|c|}{ Error } \\
\hline & & \multirow{2}{*}{$\begin{array}{l}\text { NL } \\
\text { NL }\end{array}$} & \multirow{2}{*}{$\frac{\text { NS }}{\text { NL }}$} & \multirow{2}{*}{$\frac{\mathbf{Z E}}{\mathrm{NS}}$} & \multirow{2}{*}{$\frac{\text { PS }}{\text { NS }}$} & \multirow{2}{*}{$\frac{\mathbf{P L}}{\mathrm{ZE}}$} \\
\hline \multirow{5}{*}{ 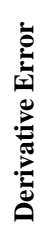 } & NL & & & & & \\
\hline & NS & NL & NL & NS & ZE & PS \\
\hline & $\mathrm{ZE}$ & NS & NS & ZE & PS & PS \\
\hline & PS & NS & ZE & PS & PS & PL \\
\hline & PL & ZE & PS & PS & PL & PL \\
\hline
\end{tabular}

Initially, a sinusoidal type of disturbance was fed to the system. The disturbance applied in the disturbance has the same frequency which was used in the development of ARX model. Figure 5 indicates the attenuation value in time and frequency domains achieved by the F-PID based controller under sinusoidal disturbance. It is observed that the F-PID based controller under sinusoidal disturbance has successfully suppressed the unwanted vibration in the horizontal flexible plate. Besides, the results prove that F-PID based controller has successfully achieved $32.14 \mathrm{~dB}$ attenuation in the system at the first mode of vibration.

The attenuation value has been reduced from $103.5 \mathrm{~dB}$ to $71.36 \mathrm{~dB}$, equivalent to $31.05 \%$ attenuation, after the introduction of vibration control. The mean squared error achieved by the controller is 0.0237 , compared with 0.6655 before the activation of controller. The input and output intervals in the fuzzy system and the mean squared error achieved by the F-PID based controller under sinusoidal disturbance are as tabulated in Table 2. The attenuation level and percentage of reduction achieved by the F-PID based controller under sinusoidal disturbance are listed in Table 3.

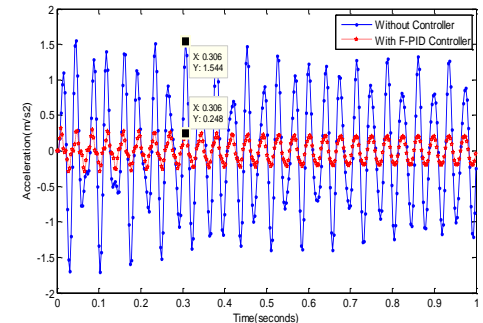

(a)

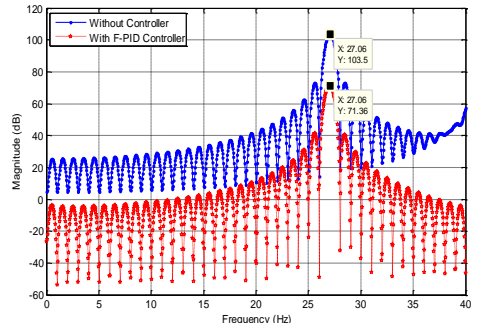

(b)

Figure 5. The F-PID based controller under sinusoidal disturbance. a) Time domain, b) Frequency domain 


\begin{tabular}{|c|c|c|c|c|c|c|}
\hline \multirow{2}{*}{ Controller } & \multicolumn{2}{|c|}{ Input Interval } & \multicolumn{3}{|c|}{ Output Interval } & \multirow{2}{*}{$\begin{array}{c}\text { Mean } \\
\text { Squared } \\
\text { Error (MSE) }\end{array}$} \\
\hline & Error & $\begin{array}{l}\text { Derivative } \\
\text { Error }\end{array}$ & $\mathbf{K}_{P}$ & $\mathbf{K}_{I}$ & $\mathbf{K}_{D}$ & \\
\hline $\begin{array}{c}\text { Without } \\
\text { Controller }\end{array}$ & - & - & - & - & - & 0.6655 \\
\hline F-PID & {$\left[\begin{array}{ll}-2 & 2\end{array}\right]$} & {$\left[\begin{array}{ll}-1 & 1\end{array}\right]$} & [3.5 4] & $\begin{array}{l}{[0.01} \\
0.03]\end{array}$ & $\begin{array}{l}{[0.005} \\
0.006]\end{array}$ & 0.0237 \\
\hline
\end{tabular}

Table 3. The PID parameters and attenuation level achieved by F-PID based controller with sinusoidal disturbance

\begin{tabular}{|c|c|c|c|c|c|c|}
\hline \multirow{2}{*}{ Controller } & \multicolumn{3}{|c|}{ PID Parameters } & $\begin{array}{c}\text { Decibel } \\
\text { Magnitude } \\
\text { (dB) }\end{array}$ & $\begin{array}{c}\text { Attenuation } \\
\text { Level (dB) }\end{array}$ & $\begin{array}{c}\text { Percentage of } \\
\text { Reduction }\end{array}$ \\
\cline { 2 - 7 } & $\mathbf{K}_{\boldsymbol{P}}$ & $\mathbf{K}_{\boldsymbol{I}}$ & $\mathbf{K}_{\boldsymbol{D}}$ & $\mathbf{1}^{\text {st }}$ mode & $\mathbf{1}^{\text {st }}$ mode & $\mathbf{1}^{\text {st }}$ mode \\
\hline $\begin{array}{c}\text { Without } \\
\text { Controller }\end{array}$ & - & - & - & 103.50 & reference & reference \\
\hline F-PID & 3.9 & 0.02 & 0.005 & 71.36 & 32.14 & $31.05 \%$ \\
\hline
\end{tabular}

Due to verify the robustness of developed control scheme, the analysis is further continued by introducing the real disturbance to the system. Figure 6 presents the performance of F-PID based controller under real disturbance in time and frequency domains, respectively. Here, it shows that the performance of the controller under real disturbance is enhanced since the percentage of reduction in the system is increased. The maximum attenuation achieved by FPID based controller is $31.99 \mathrm{~dB}$. The attenuation value has been reduced from $52.97 \mathrm{~dB}$ to $20.98 \mathrm{~dB}$, equivalent to $60.39 \%$ attenuation, after the introduction of vibration control. Besides, it is also noticed that the performance of the controller is still in maintain and robust conditions although the system is exerted with the real disturbance collected through experimental work.

In addition, it also can be seen that the vibrating frequency response in real disturbance is different from the vibrating frequency response in sinusoidal disturbance. This is caused by the different disturbance vibrating frequency response exerting into the system. The magnitude of the signal in frequency response is slightly different under real disturbance as compared with the magnitude of the signal in frequency response under sinusoidal disturbance. This is due to the effect of the control action upon the vibrating horizontal flexible plate system. The input and output intervals in the fuzzy system and the mean squared error achieved by the F-PID based controller under real disturbance are as tabulated in Table 4. In addition, the attenuation level and percentage of reduction achieved by the F-PID based controller under real disturbance are as listed in Table 5.

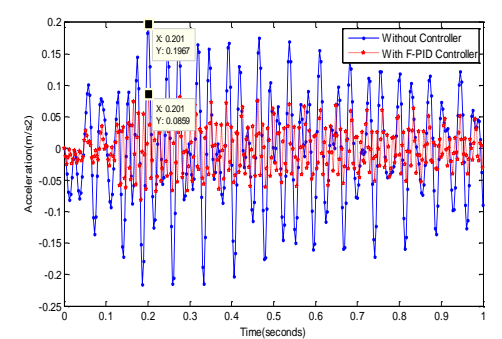

(a)

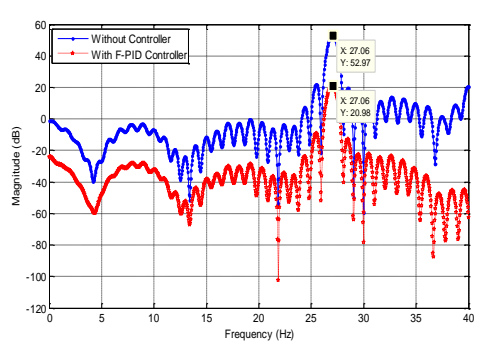

(b)

Figure 6. The F-PID based controller under real disturbance. a) Time domain, b) Frequency domain 
Table 4. The input and output interval and MSE obtained by F-PID based controller using real disturbance

\begin{tabular}{|c|c|c|c|c|c|c|}
\hline \multirow{2}{*}{ Controller } & \multicolumn{2}{|c|}{ Input Interval } & \multicolumn{3}{|c|}{ Output Interval } & \multirow{2}{*}{$\begin{array}{c}\text { Mean } \\
\text { Squared } \\
\text { Error (MSE) }\end{array}$} \\
\hline & Error & $\begin{array}{c}\text { Derivative } \\
\text { Error }\end{array}$ & $\mathbf{K}_{P}$ & $\mathbf{K}_{I}$ & $\mathbf{K}_{D}$ & \\
\hline $\begin{array}{c}\text { Without } \\
\text { Controller }\end{array}$ & - & - & - & - & - & 0.0077 \\
\hline F-PID & {$\left[\begin{array}{ll}-2 & 2\end{array}\right]$} & {$\left[\begin{array}{ll}-1 & 1\end{array}\right]$} & [3.5 4] & $\begin{array}{l}0.01 \\
0.03]\end{array}$ & $\begin{array}{l}0.005 \\
0.006]\end{array}$ & 0.0012 \\
\hline
\end{tabular}

Table 5. The PID parameters and attenuation level achieved by F-PID based controller with real disturbance

\begin{tabular}{|c|c|c|c|c|c|c|}
\hline \multirow{2}{*}{ Controller } & \multicolumn{3}{|c|}{ PID Parameters } & \multirow{2}{*}{$\begin{array}{c}\begin{array}{c}\text { Decibel } \\
\text { Magnitude } \\
(\mathrm{dB})\end{array} \\
1^{\text {st }} \text { mode }\end{array}$} & \multirow{2}{*}{$\begin{array}{c}\begin{array}{c}\text { Attenuation } \\
\text { Level (dB) }\end{array} \\
\mathbf{1}^{\text {st }} \text { mode }\end{array}$} & \multirow{2}{*}{$\begin{array}{c}\begin{array}{c}\text { Percentage of } \\
\text { Reduction }\end{array} \\
1^{\text {st }} \text { mode }\end{array}$} \\
\hline & $\mathbf{K}_{P}$ & $\mathbf{K}_{I}$ & $\mathbf{K}_{D}$ & & & \\
\hline $\begin{array}{c}\text { Without } \\
\text { Controller }\end{array}$ & - & - & - & 52.97 & reference & reference \\
\hline F-PID & 3.9 & 0.02 & 0.005 & 20.98 & 31.99 & $60.39 \%$ \\
\hline
\end{tabular}

\section{Conclusion}

This paper presents the development of hybrid controller known as Fuzzy-PID based controller for vibration cancellation of horizontal flexible plate system. The model of the system was developed using evolutionary swarm algorithm based on Auto-regressive with exogenous (ARX) input structure. The developed model was used as a platform of controller development in this study. It is noticed that the F-PID based controller was successfully suppressed the unwanted vibration in the system where the controller reduce the attenuation value of the system from $103.5 \mathrm{~dB}$ to $71.36 \mathrm{~dB}$, equivalent to $31.05 \%$ attenuation, after the introduction of vibration control. Due to verify the robustness of the controller, different type of disturbances known as real disturbance was introduced in the system. Here, it shows that the performance of the controller under real disturbance is enhanced since the percentage of reduction in the system is increased. The maximum attenuation achieved by F-PID based controller is $31.99 \mathrm{~dB}$. The attenuation value has been reduced from $52.97 \mathrm{~dB}$ to $20.98 \mathrm{~dB}$, equivalent to $60.39 \%$ attenuation, after the introduction of vibration control. Thus, it can be concluded that the F-PID based controller has successfully suppressed the undesired vibration of the horizontal flexible plate system.

\section{Acknowledgments}

The authors would like to express their gratitude to Minister of Education Malaysia (MOE), Universiti Teknologi MARA (UiTM), Universiti Teknologi Malaysia (UTM) and Universiti Malaysia Sarawak (UNIMAS) for funding the research and providing facilities to conduct this research. 


\section{References}

1. M. Y. Abdullah, M. Hussien, M. Z. Md Zain, R. Ahmad and R. Ganesh. Effect of Transducer Mass on Thin Plate Vibration. International Symposium on Information Technology. 26-28 August. Kuala Lumpur, Malaysia (2008).

2. I. Z. Mat Darus and A. A. M. Al-Khafaji. Non-Parametric Modeling of a Rectangular Flexible Plate Structure. J. Eng. Appl. of Artif. Intel. 25, 94 (2012).

3. M S. Hadi and I. Z. Mat Darus. Modelling of Horizontal Flexible Plate Structure Using Artificial Bee Colony Algorithm. Int. J. Eng. \& Tech. 7, 415 (2018).

4. M. O. Tokhi and M. A. Hossain. A Unified Adaptive Active Control Mechanism for Noise Cancellation and Vibration Suppression. J. Mech. Syst. \& Sign. Proc. 10, 667 (1996).

5. M.A. Hossain and M. O. Tokhi. Evolutionary Adaptive Active Vibration Control. Proc. Inst. Mech. Engrs. Part I. 211, 183 (1997).

6. A. Jnifene. Active Vibration Control of Flexible Structures using Delayed Position Feedback. J. Syst. \& Contr. Lett. 56, 215 (2007).

7. H. Mohd Yatim. Evolutionary Algorithms for Active Vibration Control of Flexible Manipulator. Ph.D. Thesis Department of Applied Mechanics, Faculty of Mechanical Engineering, Universiti Teknologi Malaysia (2016).

8. A. A. M. Al-Khafaji. Modeling and Control Of Underwater Flexible-Link Manipulator Employing Bio-Inspired Algorithms and PID-Based Control Schemes. Ph.D. Thesis Department of Applied Mechanics, Faculty of Mechanical Engineering, Universiti Teknologi Malaysia (2016).

9. M S. Hadi and I. Z. Mat Darus. Modelling and control of horizontal flexible plate using particle swarm optimization. Int. J. Eng. \& Tech. 7, 13 (2018).

10. S. Ra'afat. Enhancement of Transient Stability for Iraqi Power System by using FuzzyGenetic Controller. Master Thesis, University of Technology, Baghdad, Iraq (2007).

11. G. K. Mann, B. G. Hu and R. G. Gosine. Analysis of Direct Action Fuzzy PID Controller Structures. Systems, Mapn, and Cybernetics, Part B: Cybernetics, IEEE Transactions on. 29, 371 (1999).

12. A. P. Engelbrecht. Computational Intelligence. 2nd Edition, John Wiley and Sons Ltd, University of Pretoria, South Africa (2007). 